\title{
Clinical evaluation of a newly designed fluid warming kit on fluid warming and hypothermia during spinal surgery
}

\author{
Ki Tae Jung ${ }^{1,2}$, Sang Hun Kim ${ }^{1,2}$, Keum Young So ${ }^{1,2}$, Hyeong Jin So ${ }^{2}$, and \\ Soo Bin Shim ${ }^{2}$ \\ Department of Anesthesiology and Pain Medicine, ${ }^{1}$ Chosun University School of Medicine, ${ }^{2}$ Chosun University \\ Hospital, Gwangju, Korea
}

\begin{abstract}
Background: The Mega Acer Kit ${ }^{\circledR}$ (MAK) is a newly designed heated and humidified breathing circuit that warms fluid passing through the circuit lumen. In this study, we investigated the system's efficacy for the perioperative prevention of hypothermia and fluid warming.

Methods: Ninety patients undergoing spinal surgery were enrolled in this study and randomly assigned to 3 groups based on the fluid warming device used: no fluid warming system (Group C, $\mathrm{n}=30$ ), via a Standard Ranger (Group R, $\mathrm{n}=30$ ), or via the MAK (Group M, n = 30). Distal esophageal temperatures (Teso) and infusion fluid temperature (TF) were recorded at $15 \mathrm{~min}$ intervals for duration of $180 \mathrm{~min}$ during surgery. If Teso was $<35.0^{\circ} \mathrm{C}$, a forced-air convective warming device was used.

Results: Final Teso values were $34.8 \pm 0.3^{\circ} \mathrm{C}, 35.1 \pm 0.1^{\circ} \mathrm{C}$, and $35.8 \pm 0.3^{\circ} \mathrm{C}$ in groups $\mathrm{C}$, $\mathrm{R}$, and $\mathrm{M}$, respectively $(\mathrm{P}<0.01)$. Teso was significantly higher in group $\mathrm{M}$ when compared with that in groups $\mathrm{C}$ and $\mathrm{R}$ throughout the study period $(\mathrm{P}<0.05)$. The number of patients requiring a forced-air convective warming device was significantly lower in group $\mathrm{M}$ $(\mathrm{n}=0)$ when compared with that in groups $\mathrm{R}(\mathrm{n}=17)$ and $\mathrm{C}(\mathrm{n}=30)(\mathrm{P}<0.05)$. The final infusion fluid temperature was higher in group $\mathrm{M}$ when compared with that in groups $\mathrm{C}$ and $\mathrm{R}$ throughout the study period (35.4 \pm 1.0 vs. $23.0 \pm 0.3$ and $\left.32.8 \pm 0.6^{\circ} \mathrm{C} ; \mathrm{P}<0.01\right)$.

Conclusions: The MAK is more effective for preventing hypothermia and for warming fluid than the Standard Ranger.
\end{abstract}

Key Words: Esophagus, Fluid, Fluid warming system, Hypothermia, Temperature.

Corresponding author: Sang Hun Kim, M.D., Ph.D.

Department of Anesthesiology and Pain Medicine, Chosun University School of Medicine, 309, Pilmun-daero, Dong-gu, Gwangju 61452, Korea

Tel: 82-62-220-3223, Fax: 82-62-223-2333

E-mail:ksh3223@chosun.ac.kr

Received: March 30, 2015.

Revised: 1st, April 20, 2015; 2nd, May 8, 2015.

Accepted: May 21, 2015.

Korean J Anesthesiol 2015 October 68(5): 462-468 http://dx.doi.org/10.4097/kjae.2015.68.5.462

\section{Introduction}

It is common for the core body temperature to drop below $35^{\circ} \mathrm{C}$ within the first $40 \mathrm{~min}$ of administration of anesthesia to a patient. If the body temperature is not controlled intraoperatively, patients are likely to suffer postoperative hypothermia [1]. Perioperative hypothermia is a recognized and common side effect of anesthesia that inhibits normal thermoregulation. It frequently prolongs the duration of action of both anesthetics and neuromuscular blocking agents; delays postoperative recovery; and increases the incidence of surgical wound infections, coagu-

(c) This is an open-access article distributed under the terms of the Creative Commons Attribution Non-Commercial License (http://creativecommons.org/ licenses/by-nc/4.0/), which permits unrestricted non-commercial use, distribution, and reproduction in any medium, provided the original work is properly cited. 
lopathy, and cardiac events [2]. Billeter et al. [3] reported that patients with postoperative hypothermia had a 4-fold increase in mortality as well as a 2 -fold increase in the complication rate when compared to patients with postoperative normothermia. Therefore, the National Institute for Health and Clinical Excellence released guidelines for the management of inadvertent perioperative hypothermia in adults [1]. These guidelines recommend that intravenous fluids with volumes $>500 \mathrm{ml}$ should be warmed to $37^{\circ} \mathrm{C}$ using a fluid warming device, as infusion of $1 \mathrm{~L}$ of an intravenous fluid at room temperature $\left(21^{\circ} \mathrm{C}\right)$ could reduce core body temperature by $0.25^{\circ} \mathrm{C} / \mathrm{L}[1,4,5]$. Accordingly, various fluid warming devices designed to deliver fluid at a temperature of approximately $37^{\circ} \mathrm{C}$ have been developed. The use of perioperative warming devices has now become routine [6], and many studies have shown that maintaining perioperative normothermia with preventive treatment and aggressive use of warming devices is helpful for reducing morbidity and complications [3,7-9].

The standard-flow disposable fluid warming set $3 \mathrm{M}^{\mathrm{TM}}$ Rang$\mathrm{er}^{\mathrm{TM}}$ Blood/ Fluid Warming System (Standard Ranger, Arizant Healthcare, Inc., MN, USA) uses Icountercurrent metal technology for fluid warming and has been shown to significantly increase the delivered fluid temperature by increasing the infusion rate to $1 \mathrm{~L} / \mathrm{hr}[10,11]$. The Mega Acer Kit ${ }^{\circledR}$ (MAK, Ace Medical, Seoul, Korea) is a recently developed and novel fluid warming system that is able to warm fluid via the lumen of a newly designed heated and humidified breathing circuit (HHBC) inclusive of a fluid-warming unit. Therefore, we hypothesized that the MAK would be more effective at maintaining distal esophageal temperature than the Standard Ranger during anesthesia. However, the clinical and laboratory efficacy of these two systems have not yet been compared.

The present study aimed to compare the fluid warming performances and the efficacy of hypothermia prevention of the MAK and the Standard Ranger in patients undergoing spinal surgery under general anesthesia.

\section{Materials and Methods}

This prospective, randomized study was approved by our Institutional Review Board and written and informed consent was obtained from all patients. We enrolled patients classified by the American Society of Anesthesiologists as physical status I or II, who were aged between 20 and 65 years and scheduled for elective spinal surgery with duration of at least 180 min between October 2011 and March 2012. Patients with preoperative hypothermia $\left(<36.0^{\circ} \mathrm{C}\right)$ or hyperthermia $\left(>38^{\circ} \mathrm{C}\right)$, thyroid diseases, diabetes, hypertension; patients receiving medicines that could affect thermoregulation; and patients undergoing emergency surgery were excluded from the study.
Patients were randomized by means of a random number table to receive intravenous fluids either without the use of warming devices (group $\mathrm{C}, \mathrm{n}=30$ ), using Standard Ranger (set point: $41^{\circ} \mathrm{C}$, group $\mathrm{R}, \mathrm{n}=30$ ), or using MAK (set point: $38^{\circ} \mathrm{C}$, group $\mathrm{M}$, $\mathrm{n}=30$ ). Patients were administered $0.05 \mathrm{mg} / \mathrm{kg}$ of midazolam intramuscularly $30 \mathrm{~min}$ before total intravenous anesthesia with propofol and remifentanil, and mechanical ventilation was set to maintain 30 to $35 \mathrm{mmHg}$ end-tidal carbon dioxide. For delivery of $3 \mathrm{~L} / \mathrm{min}$ of $50 \%$ oxygen, a conventional HHBC (Heated Circuit Kit, Ace Medical, Seoul, South Korea) was used in groups $\mathrm{C}$ and $\mathrm{R}$, while a new HHBC with a fluid-warming unit (Mega Acer Kit, Ace Medical, Seoul, South Korea) was used in group M. After induction, fluids that had been stored for over $24 \mathrm{~h}$ in the operating theatre at $22 \pm 2^{\circ} \mathrm{C}$ were delivered at $400 \mathrm{ml} / \mathrm{h}$ through preheated warming devices according to the manufacturer's instructions. The infusion rate was not altered unless estimated blood loss exceeded allowable blood loss; in which case the infusion rate was increased, repeated $250 \mathrm{ml}$ bolus infusions of fluids were performed, or transfusions were carried out according to the patient's hemodynamic status. Affected patients were subsequently excluded from the analysis.

The temperature monitoring sites are shown in Fig. 1. These fluid temperatures were measured using a fluid thermometer (KTH 300 I, Kimo instruments, Edenbridge, UK) with a specially designed device similar to a Y-connector with a side port through which a wire Pt 100 temperature probe (KRGA-50, Kimo instruments, Edenbridge, UK) was inserted under sterile conditions, while the remaining side ports were attached directly to the intravenous tubing. Baseline temperature values at the 3 recording points were recorded before infusing the heated fluid and measurements were taken at $15 \mathrm{~min}$ intervals for a total duration of $180 \mathrm{~min}$. The distal esophageal temperature (Teso), room temperature, mean arterial pressure (MAP), and heart rate (HR) were recorded after induction and simultaneously with fluid temperature measurements. When Teso was $<35.0^{\circ} \mathrm{C}$, a forced-air convective warming device (the upper body, Bair Hugger, Arizant Healthcare, Inc., MN, USA) was applied to maintain Teso temperature above $35.0^{\circ} \mathrm{C}$.

Change in maximal declined Teso and final Teso temperatures were calculated from baseline $[\Delta$ Teso ( $\max ), \Delta$ Teso (final)]. The expected change in mean body temperature (MBT) according to fluid temperature at the $\mathrm{T} 3$ recording point was calculated for each group at the $180 \mathrm{~min}$ time point. This was done using Horowitz's formula below:

$$
\Delta \mathrm{MBT}=\frac{(\mathrm{TF}-\mathrm{TPt}) \times(\mathrm{SF}) \times(\mathrm{Vol})}{(\mathrm{SPt}) \times(\mathrm{Wt})}
$$

where $\triangle \mathrm{MBT}$ is the change in $\mathrm{MBT}, \mathrm{TF}$ is the temperature of 
A

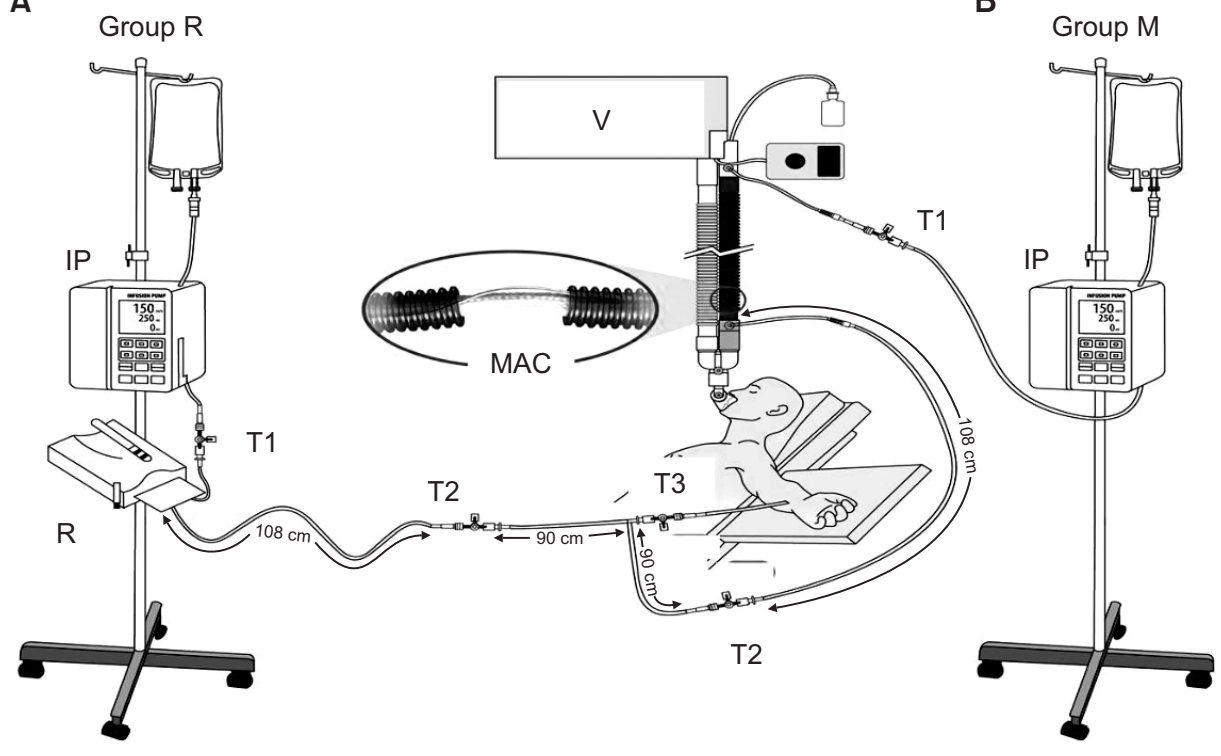

Fig. 1. Clinical and experimental set up. (A) Group R received intravenous fluids using the Standard Ranger (Arizant Healthcare Inc., MN, USA). (B) Group $M$ received intravenous fluids using the Mega Acer Kit ${ }^{\circledR}$ (Ace Medical, Seoul, Korea). Temperature monitoring sites were set up at 3 points; 1 ) the inlet point $(\mathrm{T} 1), 2)$ the outlet point $(\mathrm{T} 2,108 \mathrm{~cm}$ from the warming devices), and 3) the distal point of the warmer $(\mathrm{T} 3,198 \mathrm{~cm}$ from the warming device). IP: infusion pump, MAK: the Mega Acer Kit ${ }^{\circledR}$, R: the Standard Ranger, V: ventilator. the fluid infused, TPt is the patient's baseline core temperature $\left({ }^{\circ} \mathrm{C}\right), \mathrm{SF}$ is the specific heat of the fluid infused $\left(1.0 \mathrm{kcal} / \mathrm{L} /{ }^{\circ} \mathrm{C}\right.$ for saline), Vol is the volume of the fluid infused (in L), SPt is the specific heat of human tissue $\left(0.83 \mathrm{kcal} / \mathrm{L} /{ }^{\circ} \mathrm{C}\right)$, and $\mathrm{Wt}$ is the weight of the patient (in $\mathrm{kg}$ ) [12].

The primary outcome measure of this study was the intraoperative distal esophageal temperature. Secondary outcome measures included fluid temperatures and the number of patients requiring application of the forced-air convective warming device.

As no references were available for aiding calculation of the sample size, total sample size in this study was based on the level of statistical significance defined as $\alpha=0.05, \beta=0.2$, and the effect size of 0.25 . A minimum of 29 patients per group was required to test our hypothesis. In order to compensate for possible dropouts (5\%), 30 patients per group were enrolled in this study.

Statistical analysis was performed using the Statistical Package for the Social Sciences software package (SPSS, Version 20.0, SPSS Inc., Chicago, IL, USA). All recorded values were presented as the mean \pm standard deviation (SD) or as the number of patients. The $\chi^{2}$ and one-way analysis of variance (ANOVA) tests were used to analyze demographic data, intraoperative physiological data, infused fluid temperature values, and esophageal temperature values; but not the time-sequence data. Continuous normally distributed fluid and esophageal temperature values were compared using repeated ANOVA and the Turkey posthoc test. A P value $<0.05$ was considered statistically significant.

\section{Results}

A total of 90 patients were enrolled in the study and 1170
Table 1. Demographic and Intraoperative Data

\begin{tabular}{lccc}
\hline & $\begin{array}{c}\text { Group C } \\
(\mathrm{n}=30)\end{array}$ & $\begin{array}{c}\text { Group R } \\
(\mathrm{n}=30)\end{array}$ & $\begin{array}{c}\text { Group M } \\
(\mathrm{n}=30)\end{array}$ \\
\hline Gender (M/F) & $12 / 18$ & $16 / 14$ & $16 / 14$ \\
ASA (I/II) & $23 / 7$ & $18 / 12$ & $19 / 11$ \\
Age (yr) & $49.1 \pm 10.4$ & $47.2 \pm 10.6$ & $49.3 \pm 12.1$ \\
Height (cm) & $162.3 \pm 10.3$ & $164.6 \pm 7.7$ & $164.3 \pm 8.3$ \\
Weight $(\mathrm{kg})$ & $63.6 \pm 10.0$ & $62.5 \pm 11.1$ & $65.9 \pm 10.3$ \\
BMI & $24.1 \pm 2.1$ & $22.9 \pm 2.7$ & $24.3 \pm 2.4$ \\
EBL (ml) & $572.5 \pm 179.6$ & $590.8 \pm 132.0$ & $609.9 \pm 133.0$ \\
Urine output (ml) & $412.7 \pm 77.3$ & $436.7 \pm 71.7$ & $455.7 \pm 110.7$
\end{tabular}

Values are expressed as mean \pm SD or a number of patients. There are no significant differences among groups. Group $\mathrm{C}$ received intravenous fluids without warming. Group R received intravenous fluids using Standard Ranger. Group M received intravenous fluids using the Mega Acer $\mathrm{Kit}^{\circledR}$. ASA: American society of anesthesiologist physical status classification, BMI: body mass index, EBL: estimated blood loss.

temperature measurements were recorded during fluid infusions. No patients were excluded from the final data analysis. No statistically significant differences in the demographic data, intraoperative blood loss, and urine output was observed among the groups (Table 1).

Baseline Teso values were similar and tended to decrease across the 3 groups (group C: $36.3 \pm 0.2^{\circ} \mathrm{C}$, Group R: $36.4 \pm$ $0.2^{\circ} \mathrm{C}$, group $\mathrm{M}: 36.4 \pm 0.2^{\circ} \mathrm{C}$ ) (Fig. 2 ). Teso in group $\mathrm{M}$ was significantly higher when compared with that in groups $\mathrm{C}$ and $\mathrm{R}$ throughout the study period $(\mathrm{P}<0.05)$. The maximal declined Teso and the final Teso were significantly higher in group $\mathrm{M}$ (35.6 $\pm 0.2^{\circ} \mathrm{C}$ and $35.8 \pm 0.3^{\circ} \mathrm{C}$, respectively) with compared with groups $\mathrm{R}\left(34.9 \pm 0.2^{\circ} \mathrm{C}, 35.1 \pm 0.1^{\circ} \mathrm{C}\right)$ and $\mathrm{C}\left(34.6 \pm 0.3^{\circ} \mathrm{C}, 34.8\right.$ $\left.\pm 0.3^{\circ} \mathrm{C}\right)(\mathrm{P}<0.05$, Table 2$)$. The estimated change in MBT after 
saline infusion at a flow rate of $400 \mathrm{ml} / \mathrm{h}$ for $3 \mathrm{~h}$ was significantly lower in group $\mathrm{M}\left(0.02 \pm 0.01^{\circ} \mathrm{C}\right)$ when compared with groups $\mathrm{R}\left(0.09 \pm 0.02^{\circ} \mathrm{C}\right)$ and $\mathrm{C}\left(0.32 \pm 0.05^{\circ} \mathrm{C}\right)(\mathrm{P}<0.05$, Table 2$)$. The number of patients requiring application of a forced-air convective warming device was significantly lower in group $M(n=0)$ when compared with that in groups $\mathrm{R}(\mathrm{n}=17)$ and $\mathrm{C}(\mathrm{n}=30)(\mathrm{P}$ $<0.01$, Table 2).

No significant difference in baseline fluid temperature before warming (TF1) was observed among the 3 groups (Table 3 ). The TF2 and TF3 were significantly higher in group $\mathrm{M}$ when compared with those in groups $\mathrm{C}$ and $\mathrm{R}$ throughout the study period $(\mathrm{P}<0.05$, Figs. $3 \mathrm{~A}$ and $3 \mathrm{~B})$. The overall mean values of TF 2 and TF3 were significantly higher in group $M$ when compared with

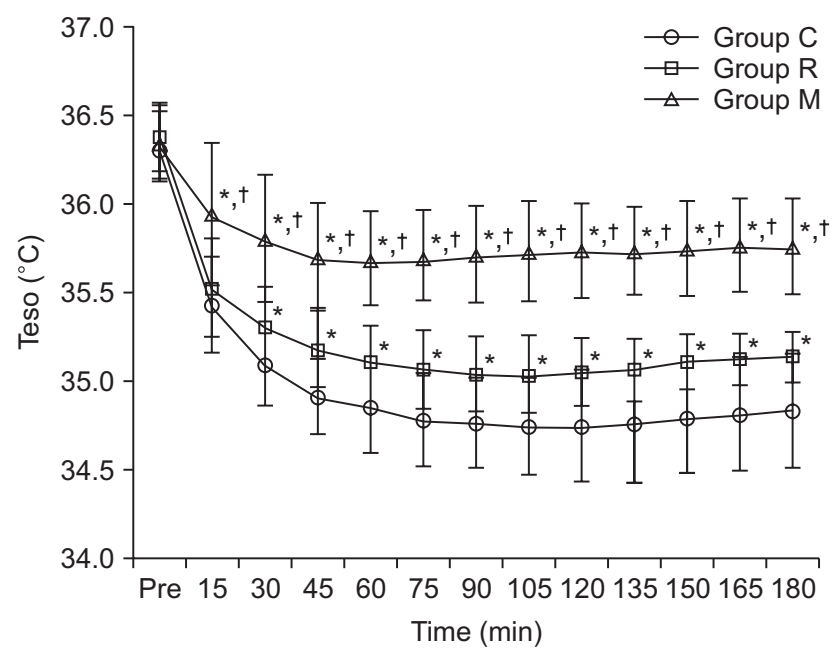

Fig. 2. Changes in distal esophageal temperature (Teso). Teso tended to decrease across all 3 groups. Teso in group $\mathrm{M}$ was significantly higher when compared with groups $\mathrm{C}$ and $\mathrm{R}$ throughout the study period. Group C received intravenous fluids without warming and Group R received intravenous fluids using the Standard Ranger. Group $\mathrm{M}$ received intravenous fluids using the Mega Acer $\mathrm{Kit}^{\circledR} . * \mathrm{P}<0.05$ compared with group $\mathrm{C},{ }^{\dagger} \mathrm{P}<0.05$ compared with group $\mathrm{R}$. those in groups $\mathrm{C}$ and $\mathrm{R}\left(37.4 \pm 1.7^{\circ} \mathrm{C}\right.$ and $35.4 \pm 1.0^{\circ} \mathrm{C}$ vs. 23.5 $\pm 0.3^{\circ} \mathrm{C}$ and $23.0 \pm 0.3^{\circ} \mathrm{C}, 34.7 \pm 0.8^{\circ} \mathrm{C}$ and $32.8 \pm 0.6^{\circ} \mathrm{C}$, respectively, $\mathrm{P}<0.05$, Table 3 ).

Room temperature was maintained at $23.1 \pm 0.8^{\circ} \mathrm{C}, 23.1 \pm$ $0.6^{\circ} \mathrm{C}$, and $23.2 \pm 0.7^{\circ} \mathrm{C}$, respectively, with no significant difference among the groups (data not shown).

In addition, no significant changes in MAP or HR were observed among the 3 groups (data not shown).

\section{Discussion}

This study showed that the MAK, a new HHBC containing a fluid warming device, was more effective than the Standard Ranger with a conventional $\mathrm{HHBC}$ at preventing intraoperative hypothermia $\left(<35.0^{\circ} \mathrm{C}\right)$ during fluid infusion at a flow rate of $400 \mathrm{ml} / \mathrm{h}$ in patients undergoing spinal surgery.

The devices that have been used in our hospital to warm intravenous fluids operate on a number of principles including dry heat, countercurrent water baths, countercurrent metal technology, or magnetic induction. The MAK consists of a fluid line

Table 3. The Temperature $\left({ }^{\circ} \mathrm{C}\right)$ of Infusing Fluid at the Inlet, Outlet, and Distal Points from Each Warming Device

\begin{tabular}{lccc}
\hline & $\begin{array}{c}\text { Group C } \\
(\mathrm{n}=30)\end{array}$ & $\begin{array}{c}\text { Group R } \\
(\mathrm{n}=30)\end{array}$ & $\begin{array}{c}\text { Group M } \\
(\mathrm{n}=30)\end{array}$ \\
\hline TF1 (Inlet) & $23.8 \pm 0.1$ & $24.0 \pm 0.7$ & $24.0 \pm 0.8$ \\
TF2 (Outlet) & $23.5 \pm 0.3$ & $34.7 \pm 0.8^{*}$ & $37.4 \pm 1.7^{*,+}$ \\
TF3 (Distal) & $23.0 \pm 0.3$ & $32.8 \pm 0.6^{*}$ & $35.4 \pm 1.0^{*,+}$ \\
\hline
\end{tabular}

Values are expressed as mean \pm SD. Group $C$ received intravenous fluids without warming. Group $\mathrm{R}$ received intravenous fluids using Standard Ranger. Group M received intravenous fluids using the Mega Acer Kit ${ }^{\circledR}$. TF1: temperature at the inlet point (T1) of the warming devices, TF2: temperature at the outlet point (T2) $108 \mathrm{~cm}$ from the warming devices, TF3: temperature at distal point (T3) $198 \mathrm{~cm}$ from the warming device. ${ }^{*} \mathrm{P}<0.05$ compared with the group $\mathrm{C},{ }^{\dagger} \mathrm{P}<0.05$ compared with the group R.

Table 2. Intraoperative Esophageal Temperatures and the Estimated Change in Mean Body Temperature $\left({ }^{\circ} \mathrm{C}\right)$

\begin{tabular}{lccc}
\hline & $\begin{array}{c}\text { Group C } \\
(\mathrm{n}=30)\end{array}$ & $\begin{array}{c}\text { Group R } \\
(\mathrm{n}=30)\end{array}$ & $\begin{array}{c}\text { Group M } \\
(\mathrm{n}=30)\end{array}$ \\
\hline Teso, baseline & $36.3 \pm 0.2$ & $36.4 \pm 0.2$ & $36.4 \pm 0.2$ \\
Teso, maximal declined & $34.6 \pm 0.3$ & $34.9 \pm 0.2^{*}$ & $35.6 \pm 0.2^{*,+}$ \\
Teso, final & $34.8 \pm 0.3$ & $35.1 \pm 0.1^{*}$ & $35.8 \pm 0.3^{*,+}$ \\
$\Delta$ Teso (max) & $-1.7 \pm 0.4$ & $-1.4 \pm 0.3^{*}$ & $-0.8 \pm 0.2^{*,+}$ \\
$\Delta$ Teso (final) & $-1.5 \pm 0.4$ & $-1.2 \pm 0.2^{*}$ & $-0.6 \pm 0.3^{*,+}$ \\
$\Delta$ MBT (estimated, final) & $-0.32 \pm 0.05$ & $-0.09 \pm 0.02^{*}$ & $-0.02 \pm 0.01^{*,+}$ \\
Intervention for hypothermia (n) & 30 & $17^{*}$ & $0^{*, \dagger}$ \\
\hline
\end{tabular}

Values are expressed as mean \pm SD or a number of patients. Group C received intravenous fluids without warming. Group $\mathrm{R}$ received intravenous fluids using Standard Ranger. Group M received intravenous fluids using the Mega Acer Kit ${ }^{\circledR}$. Teso: distal esophageal temperature, $\Delta$ Teso (max): Change of maximal declined Teso from baseline, $\Delta$ Teso (final): Change, of final Teso from baseline, $\Delta$ MBT (estimated, final): estimated change in mean body temperature in patients after $3 \mathrm{hr}$ at $400 \mathrm{ml} / \mathrm{hr}$ with saline. ${ }^{*} \mathrm{P}<0.05$ compared with the group $\mathrm{C},{ }^{\dagger} \mathrm{P}<0.05$ compared with the group $\mathrm{R}$. 
A

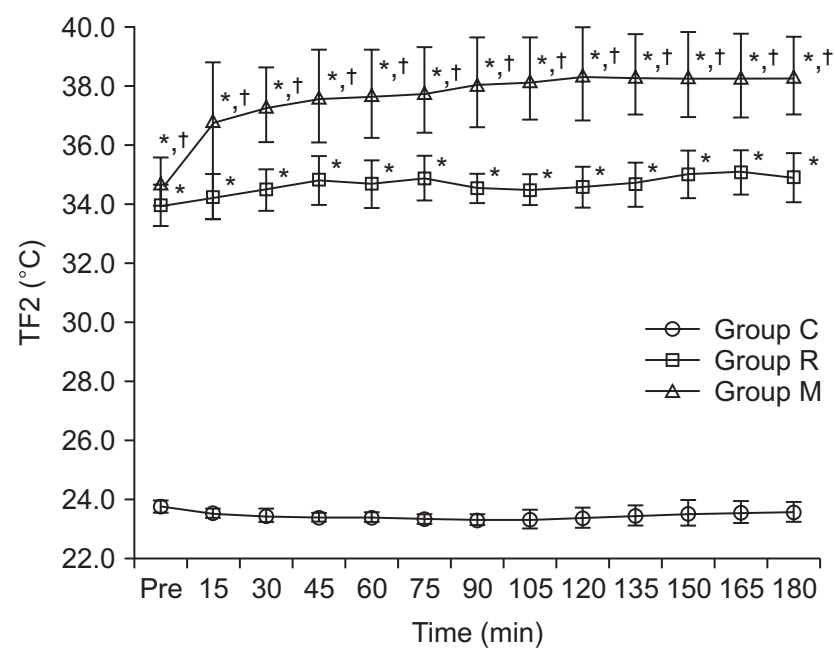

B

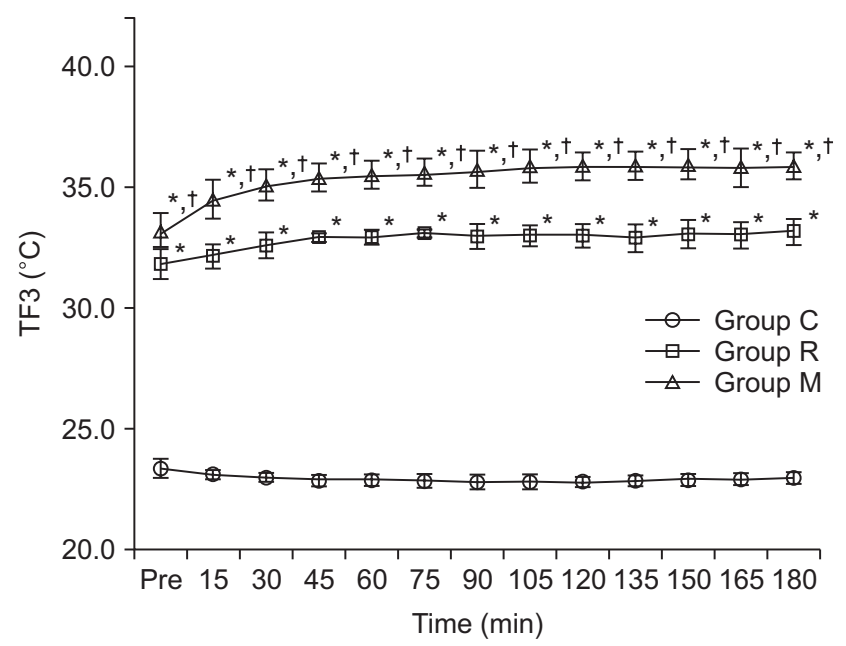

Fig. 3. Changes in fluid temperatures (TFs). TF2 (panel A) and TF3 (panel B) were significantly higher in group M at all time points when compared with Groups C and R. Values in group R were significantly higher when compared with group C. Group C received intravenous fluids without warming and Group R received intravenous fluids using the Standard Ranger. Group M received intravenous fluids using the Mega Acer Kit ${ }^{\circledR}$. TF1, fluid temperature at the inlet point (T1) of the warming devices; TF2, fluid temperature at the outlet point (T2) $108 \mathrm{~cm}$ from the warming devices; $\mathrm{TF} 3$, fluid temperature at the distal point (T3) $198 \mathrm{~cm}$ from the warming devices. $* \mathrm{P}<0.05$ compared with the group $\mathrm{C},{ }^{\dagger} \mathrm{P}<0.05$ compared with the group R.

(100 cm long with a volume of $5 \mathrm{ml}$ ) that is placed along a heating wire, which is wrapped in cotton within a humidified and heated circuit, and is equipped with a temperature controller. This system is designed to deliver warmed and humidified gas to the patient. The MAK primarily warms the fluid directly using heated convective air currents as the fluid passes through the inspiratory gas limb. In this study, we used room-temperature saline to compare the capabilities of the new MAK, which is designed to warm the fluid via the heated circuit lumen, and the Standard Ranger, which uses countercurrent metal technology. The MAK was able to maintain higher outlet and distal fluid temperatures as well as a higher intraoperative Teso at a flow rate of $400 \mathrm{ml} / \mathrm{h}$ without the use of additional body warming devices when compared to the Standard Ranger.

The ideal fluid warming device for intraoperative use would be capable of delivering $37^{\circ} \mathrm{C}$ fluids over a wide range of flow rates and clinical conditions $[13,14]$. Changes in the temperature of the delivered fluid can be influenced by device-specific maximum flow rates as well as the outflow tubing length extending from the warming device to the temperature recording points [10-12]. Therefore, choice of a fluid warming device capable of maintaining the temperature at $37^{\circ} \mathrm{C}$ should be based on the device-specific maximum flow rate. Turner at al. [11] suggested that the Bair Hugger, which claims maximal flow rates up to $1 \mathrm{~L} / \mathrm{h}$ $(17 \mathrm{ml} / \mathrm{min})$, is suitable only for prolonged minor surgery and that devices with alleged flow rates of $15-1,500 \mathrm{ml} / \mathrm{min}$ should be selected when there is a risk of massive fluid and blood loss. Secondly, varying lengths of outflow tubing also affects the fluid temperature at the point of entering the patient in a length-dependent manner $[10,12]$. To control these contributing factors, we used extension lines and 3-way connectors to achieve equal lengths of tubing extending from each device to the outlet point $(108 \mathrm{~cm})$, extending from the outlet point to the distal point (90 $\mathrm{cm}$ ), and finally extending from the distal point to the patient's intravenous cannula $(30 \mathrm{~cm})$. The infusion rate was then set at $400 \mathrm{ml} / \mathrm{h}$ as not only does intravenous fluid administration at a rate of $4 \mathrm{ml} / \mathrm{kg} / \mathrm{h}$ reduces postoperative mortality, but we do routinely employ restrictive fluid management in cases without the risk of massive blood loss [15]. Under these conditions, the present study further showed that the delivery temperature of $37^{\circ} \mathrm{C}$ at the outlet point (108 $\mathrm{cm}$ from the warming device) can be achieved using the MAK (set to $38^{\circ} \mathrm{C}$ ) but is not achievable using the Standard Ranger (set to $41^{\circ} \mathrm{C}$ ). Therefore, the MAK may be suitable for preventing intraoperative hypothermia during minor surgery with no anticipated massive bleeding or fluid loss. However, it should be noted that the delivery temperature of $37^{\circ} \mathrm{C}$ at the distal point (198 $\mathrm{cm}$ from the warming device) was not achieved using either device. Furthermore, the temperature of the delivered intravenous fluid decreased from 34.7 to $32.8^{\circ} \mathrm{C}$ using the Standard Ranger and from 37.4 to $35.4^{\circ} \mathrm{C}$ using the MAK over a distance of $90 \mathrm{~cm}$ from the outlet point.

Although the use of the MAK facilitated achieving an outlet temperature of $37.4^{\circ} \mathrm{C}$ at $400 \mathrm{ml} / \mathrm{h}$, the distal temperature of $35.4^{\circ} \mathrm{C}$ was insufficient to maintain normothermia during the intraoperative period at a room temperature of approximately $23^{\circ} \mathrm{C}$. As a result, Teso tended to decrease across all groups, with 
impaired central thermoregulation (which controls body heat redistribution) the likely cause during anesthesia [16]. The expected change in MBT calculated using Horowitz's formula [12] (previously mentioned in the materials and methods section) was $-0.02 \pm 0.01^{\circ} \mathrm{C}$ in group $\mathrm{M},-0.09 \pm 0.02^{\circ} \mathrm{C}$ in group $\mathrm{R}$, and $-0.32 \pm 0.05^{\circ} \mathrm{C}$ in group C. In addition, Kim et al. [17] recently reported that the core body temperature at the end of surgery decreased by $0.5 \pm 0.5^{\circ} \mathrm{C}$ from baseline values in a study using the MAK. In contrast, our study found that use of the MAK resulted in a $0.7^{\circ} \mathrm{C}$ temperature increase when compared with the Standard Ranger and the need for intervention to treat hypothermia was less frequent. The observed change in the Teso was $-0.6 \pm 0.3^{\circ} \mathrm{C}$ in group $\mathrm{M},-1.2 \pm 0.2^{\circ} \mathrm{C}$ in group $\mathrm{R}$, and $-1.5 \pm$ $0.4^{\circ} \mathrm{C}$ in group $\mathrm{C}$. These discrepancies between the expected and observed changes could be attributed to the patient's inability to maintain their core temperature, as well as to heat loss through exposed body surfaces during anesthesia and spinal surgery. Unfortunately, use of the MAK and Standard Ranger devices did not prevent redistribution hypothermia and the Teso decreased by approximately 0.8 and $1.4^{\circ} \mathrm{C}$ in groups $\mathrm{M}$ and $\mathrm{R}$, respectively. Accordingly, it is not surprising that warming the infusion fluid using the Standard Ranger resulted in a higher frequency of use of the forced-air convective warming device.
This study had several limitations. First, we used a fixed flow rate, while flow rates do vary in clinical practice. Hence, the range of flow rates at which the MAK is capable of warming intravenous fluid to $37^{\circ} \mathrm{C}$ remains to be determined. Second, the risk of air embolus, which may form as the MAK does not include a filter assembly, was not evaluated. However, the risk of formation of air emboli is increased in devices that rapidly deliver warmed fluid using a pressurized intravenous infusion method, with one fatality from an air embolus reported to date [18]. In this regard, the MAK is not designed to infuse intravenous fluid rapidly. Finally, we cannot provide evidence of the safety and efficacy of warming blood products as there is no clinical or laboratory data available. Therefore, until the relevant data becomes available, we recommend that the MAK should be used for maintaining fluid balance in cases where high flow rates are not required. We further recommend the use of an additional air filter to prevent air embolus formation.

In conclusion, our study showed that the Mega Acer Kit, a new HHBC containing a fluid warming device, maintained the distal esophageal temperature more effectively and decreased the incidence of a forced-air convective warming device application more significantly than the Standard Ranger, at a flow rate of $400 \mathrm{ml} / \mathrm{h}$ in patients undergoing spinal surgery.

\section{References}

1. National Institute for Health and Clinical Excellence. Inadvertent periopeartive hypothermia: The management of inadvertent perioperative hypothermia in adults. NICE clinical guideline 652008 (April). Available from http://www.nice.org.uk/guidance/cg65.

2. Reynolds L, Beckmann J, Kurz A. Perioperative complications of hypothermia. Best Pract Res Clin Anaesthesiol 2008; $22: 645-57$.

3. Billeter AT, Hohmann SF, Druen D, Cannon R, Polk HC Jr. Unintentional perioperative hypothermia is associated with severe complications and high mortality in elective operations. Surgery 2014; 156: 1245-52.

4. Camus Y, Delva E, Cohen S, Lienhart A. The effects of warming intravenous fluids on intraoperative hypothermia and postoperative shivering during prolonged abdominal surgery. Acta Anaesthesiol Scand 1996; 40: 779-82.

5. Sessler DI. Mild perioperative hypothermia. N Engl J Med 1997; 336: 1730-7.

6. Putzu M, Casati A, Berti M, Pagliarini G, Fanelli G. Clinical complications, monitoring and management of perioperative mild hypothermia: anesthesiological features. Acta Biomed 2007; 78: 163-9.

7. Rajagopalan S, Mascha E, Na J, Sessler DI. The effects of mild perioperative hypothermia on blood loss and transfusion requirement. Anesthesiology 2008; 108: 71-7.

8. Frank SM, Fleisher LA, Breslow MJ, Higgins MS, Olson KF, Kelly S, et al. Perioperative maintenance of normothermia reduces the incidence of morbid cardiac events. A randomized clinical trial. JAMA 1997; 277: 1127-34.

9. Kurz A, Sessler DI, Lenhardt R. Perioperative normothermia to reduce the incidence of surgical-wound infection and shorten hospitalization. Study of Wound Infection and Temperature Group. N Engl J Med 1996; 334: 1209-15.

10. Bissonnette B, Paut O. Active warming of saline or blood is ineffective when standard infusion tubing is used: an experimental study. Can J Anaesth 2002; 49: 270-5.

11. Turner M, Hodzovic I, Mapleson WW. Simulated clinical evaluation of four fluid warming devices*. Anaesthesia 2006; 61: 571-5.

12. Horowitz PE, Delagarza MA, Pulaski JJ, Smith RA. Flow rates and warming efficacy with Hotline and Ranger blood/fluid warmers. Anesth Analg 2004; 99: 788-92.

13. Bieberich MT, Van Duren AP. Thermal control and design considerations for a high-performance fluid warmer. Biomed Instrum Technol 2003; 37: 103-12.

14. Schnoor J, Macko S, Weber I, Rossaint R. The air elimination capabilities of pressure infusion devices and fluid-warmers. Anaesthesia 2004; 59: 817-21. 
15. Nisanevich V, Felsenstein I, Almogy G, Weissman C, Einav S, Matot I. Effect of intraoperative fluid management on outcome after intraabdominal surgery. Anesthesiology 2005; 103: 25-32.

16. Buggy DJ, Crossley AW. Thermoregulation, mild perioperative hypothermia and postanaesthetic shivering. Br J Anaesth 2000; 84: 615-28.

17. Kim E, Lee SY, Lim YJ, Choi JY, Jeon YT, Hwang JW, et al. Effect of a new heated and humidified breathing circuit with a fluid-warming device on intraoperative core temperature: a prospective randomized study. J Anesth 2015 [Epub ahead of print].

18. Adhikary GS, Massey SR. Massive air embolism: a case report. J Clin Anesth 1998; 10: 70-2. 